therapeutic amputation of the foreskin is not obligatory.

It was disappointing to see this onesided article which appears to suggest the taxpayer should support this barbaric and inhumane practice. The two articles in the $B M J$ last year were far better. ${ }^{2,3}$

I look forward to eventually seeing a legal case against this affront on the right of a child to bodily integrity.

And please - call it what it is.

'Circumcision' sounds so euphemistically innocuous.

\section{John Fitton,}

Dryland Surgery, 1 Field Street, Kettering, NN16 8JZ

E-mail: John.Fitton@gp-K83039.nhs.uk

\section{REFERENCES}

1. Anwar MS, Munawar F, Anwar Q. Circumcision: religious obligation or 'the cruellest of cuts'? Br J Gen Pract 2010; 60(570): 59-61.

2. Patrick K. Is infant male circumcision an abuse of the rights of the child? No. BMJ 2007; 335(7631): 1180.

3. Hinchley G. Is infant male circumcision an abuse of the rights of the child? Yes. BMJ 2007; 335(7631): 1181.

DOI: 10.3399/bjgp10X483265

Doctors Anwar, Munawar, and Anwar plead for NHS resources to be diverted towards increasing the provision of religious circumcision. ${ }^{1}$ Apart from their theological justifications, their main arguments seem to relate to the risks associated with the procedure being carried out by inexperienced practitioners and that 'it is not our duty to tell a patient which decision to make, but merely to carry out said decision to the best of our ability.' This is an extraordinary argument, and we are left wondering how the authors would respond to a request for amputation of a healthy limb, female genital mutilation, or assisted suicide.

There is no medical justification for circumcising healthy neonates in the UK. While some argue that there might be a small health benefit in countries with endemic HIV infection, and possibly some reduction in risk of urinary tract infection, there is no doubt that the risk of harm greatly exceeds the health benefits in the developed world. Infants cannot give consent to surgical procedures, and there is no ethical argument for performing an irreversible procedure which might impair later sexual function (or at least sexual pleasure) before a child is old enough to give consent. Prioritising parents' religious beliefs over the health needs of their child disregards fundamental ethical principles of non-malificence and respect for patient autonomy.

The only argument for the involvement of the NHS in religious circumcision is harm reduction, and it is for that reason that I refer patients to paediatric surgeons when parents request it. There is a strong argument for the practice of male infant circumcision being treated by the law in the same way as female genital mutilation.

\section{Philip Wilson,}

GP, Senior Research Fellow

1 Horselethill Road, Section of General

Practice and Primary Care, University of

Glasgow, Glasgow, G12 9LX.

E-mail:p.wilson@clinmed.gla.ac.uk

\section{REFERENCE}

1. Anwar MS, Munawar F, Anwar Q. Circumcision: a religious obligation or 'the cruellest of cuts'? $\mathrm{Br} J \mathrm{Gen}$ Pract 2010; 60(570): 59-61.

DOI: 10.3399/bjgp10X483274

The essay on circumcision in the January 2010 edition of the BJGP clamours for 'the right to ensure that the procedure is carried out by an experienced surgeon .... If circumcision is indeed a quintessentially natural act of human cleanliness obliged by the religious tenet of Fitrah, why should it need a well-trained surgeon (or Rabbi) to perform what is purported to be one of five simple acts of human hygiene? And why is there an absence of agitation - on religious grounds - for the State to provide intensive regulation of people performing the other four Fitrah acts (nailcutting, shaving of pubic hair, plucking of axillary hair, and beard trimming)?

\section{Vidhu Mayor,}

The Ann Jones Family Health Centre, 52 Chesterton Road, Sparkbrook, Birmingham, West Midlands, B12 8HE. E-mail:Vidhu.Mayor@hobtpct.nhs.uk

\section{REFERENCE}

1. Anwar MS, Munawar F, Anwar Q. Circumcision: religious obligation or 'the cruellest of cuts'? Br J Gen Pract 2010; 60(570): 59-61.

DOI: 10.3399/bjgp10X483283

\section{Stevens-Johnson syndrome secondary to oseltamivir $\left(\right.$ Tamiflu ${ }^{\circledR}$ )}

We write to highlight a serious cutaneous side effect of the drug oseltamivir or Tamiflu ${ }^{\circledast}$ which has recently been in widespread use due to the swine influenza epidemic.

A 17-year-old male presented to hospital with an erythematous rash over his limbs and trunk, oral ulceration, facial swelling, and blurred vision. He was well with no significant past medical history. Two weeks previously he had experienced a viral illness of headache, fever, and myalgia which was treated with oseltamivir (Tamiflu ${ }^{\circledR}$ ) in the community. The day after completing the course he developed these symptoms. Other than paracetamol he had taken no other medication. Stevens-Johnson syndrome secondary to oseltamivir was diagnosed. He was found to have corneal ulceration requiring steroid eye drops and required admission and other supportive treatment before eventually recovering several weeks later.

Stevens-Johnson syndrome is a rare but recognised complication of oseltamivir (Tamiflu ${ }^{\circledast}$ ) and the condition does have an associated mortality. To date there are no figures regarding adverse reactions of this nature, as most information comes from small previous studies. ${ }^{1}$ The most common events recorded are nausea and vomiting. A Cochrane Review showed that oseltamivir (Tamiflu $\left.{ }^{\oplus}\right)$ slightly reduces time to alleviation of symptoms and is of use as post-exposure prophylaxis, but concludes low effectiveness. ${ }^{2}$ There have been recent calls for caution in extensive 